\section{LIVING LIGHTS.}

Living Lights: a Popular Account of Phosphorescent Animals and Vegetables. By C. F. Holder. (London : Sampson Low, Marston, Searle, and Rivington, t887.)

7 HIS pleasant volume of 167 pages is intended for young students of science, "their unscientific elders, and the boys and girls in general who have not yet had their interest aroused in Nature's works." The ficld covered is very wide, and the book is truly Germanic in its meanderings. The author would appear to be under the spell of those who "not only know all that is known by other people, but also all that they themselves imagine, which nobody else can possibly know." When it is said that the results obtained by the expeditions of the Challenger, Talisman, Albatross, Travailleur, and Magenta, are incorporated, no one can raise the charge of antiquity. The author discusses all possible sides of his subject, from luminous man to cosmic dust in its relation to sun-glow and even luminous paint itself, which was, as is wcll known, anticipated by the Chinese (oh, Mr. Balmain !). It must not, however, be imagined that the volutue is a mere compilation. Quite the reverse; for, while the author embodies much that is original, he incorporates manuscript notes, placed at his disposal by our veteran Gosse, and by luminologists such as Giglioli, Dubois, and others.

Technicalities are for the most part relegated to an appendix, with full references to authorities; the result being that while the book, as a whole, furnishes the specialist with a work of reference the borly of it is rendered assimilable by the feeblest tyro. The subject is intraduced by a consideration of the bottom of the ocear, which the author naïvely terms the "lower firmament"-an idea which he elaborates in the subsequent chapters, treating of "meteors" and "fixed luminaries" of the sea. We meet with many friends of our youth, such as, for example, M. de Tessan's well-worn picture of the phosphorescent sea at Simon's Town, with its accompanying description.

By way of relieving monotony, anecdotes and similes are frccly intercalated with the text. Some of the latter are very happy, as, for example, the comparison drawn between the blind-man and the Bathypterus (p. 92). On p. 13 we read: "By having a companion to kecp up a continuous motion of the (luminous) water, I have almost been able to read the print of a newspaper by the light of these disintegrated (animal) forms "-a literal stern reality this, sufficicnt to break the heart of a Ruskin.

The author appears to be suffering under a phosphorescence mania. He leads off with the rather extravagant statement, "Among the revelations of modern science none have a more absorbing interest than those relating to the illumination of the decp sea." He is, moreover, a genuine enthusiast, and, like all such, sees the salvation of his race in his own hobby, for he gives it as his opinion (p. 4I) that "the discovery of the secret of phosphorescence, and its practical application to the wants of mankind, would result in revolutionizing present systems ; a heatless, inexpensive, inextinguishable light being the perfection of possibilities in this direction.' Similar sentiments are expressed in the peroration : these we commend to the physicist.
The book is exceedingly well got up, and illustrated by twenty-six plates, most of which have been cspecially designed for it. One of these, representing the now famous giant Pyrosoma of the Challenger, in size proportionate to that of a man, is especially striking, and the publishers have, very properly, reproduced it on the cover. We would, however, suggest that, in the case of sponges and corals more especially, the animals themselves, and not their mere skeletons, should be delineated; the course here adopted is too suggestive of a "matching" of ordinary museum specimens for the sake of effect. Here and there we note a looseness of style and expression such as is frequently met with in a first issue. The book-strictly a general treatise on luminosity-is a conscientious exposition of a fascinating subject, sound though superficial, and in no sense sensational. We wish it success.

\section{OUR BOOK SHELF.}

Food Adulteration and its Detection. By J. P. Battershall, Ph.D., F.C.S. (New York: Spon, 1887.)

THE most striking points of this book are the photographic reproductions of various food-stuffs: starchgrains, fat-crystals, also margarine, milk, tea-leaves, \&c. In the introduction Dr. Battershall laments the general inefficient state of the law in America, which would apply very much more forcibly to us, regarding adulteration.

The author does very good service in his introduction, drawing attention to the statistics of recent adulteration. From one table, taken from the work of the Public Analysts' Socicty in England, it appears the percentage of adulteration has not decreased in any appreciable clegree, having been 18.10 per cent. in $1875-76$, and 17.47 in 1880 , and $16{ }^{4}$ in 1883 . The Annual Report of the New York City Board of Health for I 885 furnishes some statistics of adulteration which are by no means pleasant, and show a not very high commercial morality, although the majority are said not to be injurious adulterations-merely fraudulent. The author is quite right when he says "that attempts to awaken public interest in the subject are only of real service as they are conducive to the adoption of more advanced and improved measures for the suppression of the practice."

Generally, the subjects are treated in the book in a very practical manner, and a good deal of information is also contained under each heading. Regarding the adulteration of wines, for instance, a good many interesting receipts for making wines are given, and similarly in the case of spirits and liquors. The section on water is a good részmé of processes of water analysis. Prominence is rightly given to Prof. Mallet's very sensible conclusions as to the value of analytical methods in respect to the hygienic character. Dr. Koch's biological method, cultivation in prepared gelatine, is mentioned, and a plate showing the living forms in Croton water and Brooklyn water is given, but we are not frightened by any alarmist theories or statements as to the injurious nature of these organisms ; indeed, we are told that the greater number are unobjectionable, and frequently even of service, which is doubtless the case. The really active Bacteria are much less impressive in appearance.

There is a pretty long chapter on legislation in the United States on adulteration, which is not of much use, but is still interesting, to an English reader. The bibliography is very useful. Altogether it is a readable and useful book, and will doubtless meet with a good reception. W. R. H. 